Chapter 7

\title{
The Need to Measure and Manage the Cumulative Impacts of Resource Development on Public Health: An Australian Perspective
}

\author{
Susan Kinnear, Zobaidul Kabir, Julie Mann and \\ Lisa Bricknell
}

Additional information is available at the end of the chapter

http://dx.doi.org/10.5772/54297

\section{Introduction}

Australia is home to several resource-intensive regions that feature vast mineral, ore and/or coal deposits pooled in one physical location (Figure 1). These areas are usually characterised by multiple medium- to large-scale extraction and processing facilities, and typically include extensive road, rail and port infrastructure. The Australian resources sector has been defined by the Commonwealth of Australia [1] as:

'mining, oil and gas operations, including operating mines, quarries, oil and gas wells, as well as constructing those operations...

(and) mining support activities such as fee-for-service activities and exploration'.

Australia's resource regions are already of significant economic value, with the latest estimates for exports in resources and energy being placed at approximately $\$ 200$ billion for 2011-12 [2]. Ongoing growth is also expected, particularly in the states of Western Australia and Queensland, and this is being driven by the strong relationship between Australian and Chinese markets, together with the rise of the Indian and Chinese middle class; a high demand for natural resources (coal, power, water) and the mobility of the international skilled workforce [3].

The socio-economic and other changes associated with large-scale mineral resource extraction are key issues for regional development in Australia, and well as for other na- 
tions whose regions are undergoing a similar transition from rural-based to resourcebased (for example Canada and Mongolia). In Australia, public interest and discussion on these issues has been accelerated by a Parliamentary Inquiry underway since 2011 into the use of fly-in, fly-out (FIFO) and drive-in, drive-out (DIDO) workforce practices in the regional resource sector. For example, the terms of reference for this Inquiry includes exploring the 'impacts, costs and benefits' related to the use of non-resident labour; acquiring information about services and infrastructure provision; and developing of strategies to maximise the benefits of FIFO/DIDO arrangements for employees, their families, their communities and the resources industry.

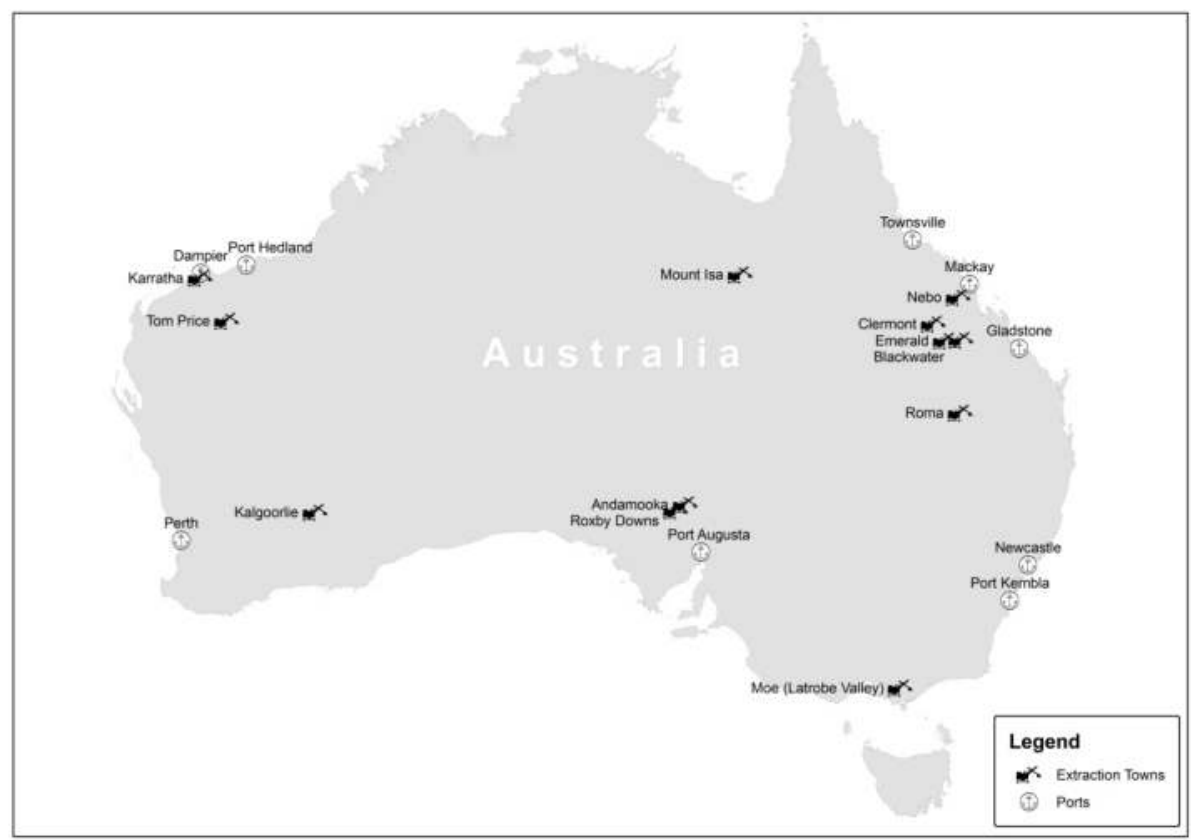

Figure 1. Examples of mining communities and ports underpinning key resource regions in Australia

Clearly, ensuring the best possible public health outcomes in resource regions is of critical importance for employers, employees and mining families as well as the broader community. However, most data relating to public health impacts - including the majority of evidence lodged in submissions to the Inquiry - are anecdotal. This likely reflects the lack of an agreed and comprehensive methodology for identifying, monitoring or managing health impacts in the context of Australian (and other) resource regions. To address this gap, this chapter explores the current evidence for public health impacts related to cumulative resource activity in regional Australia, and highlights the possible mechanisms by which this emerging health issue can be better studied and addressed. 


\section{Cumulative public health impacts associated with the resource sector}

Large scale natural resource extraction activities (for example, mining, oil and gas) can have significant impacts on the health and well-being of both resource sector employees, as well as the communities living in surrounding areas. For the purposes of this chapter, the definition of 'cumulative impacts' shall be adopted from that provided in [4]:

'cumulative impacts are the successive, incremental and combined impacts of one, or more, activities on society, the economy and the environment... (these) may be the product of past, present or future activities... can be both positive and negative and can vary in intensity as well as spatial and temporal extent'.

Cumulative impacts can therefore occur at the project-level (for example where repeated activities are undertaken at the same site); regional-level (for example multiple projects in close proximity); or even be of wider manifestation (for example global climate change). $\mathrm{Cu}$ mulative impacts arise from both natural events as well as human activities [5], but the most critical part of the definition is that the impacts are associated with more than one activity over time. As noted by [5]: 'one impact by itself may not be a cause for concern; it might even seem insignificant. However, the addition of many small impacts over time adds to the end result - cumulative effects and an increase for concern. Cumulative impacts can also arise from interactions between issues, which may trigger a new 'tipping point' and the transition to a substantially different situation [4].

With respect to public health issues, a range of cumulative impacts can (and are) emerging due to rapid growth in the Australian resource sector. The range of public health concerns associated with the resources sector in Australia can be considered under the categories of direct and indirect impacts for resource sector employees; and direct and indirect impacts to communities that host mining operations; as well as positive impacts and other linkages. Whilst the extent of public health impacts of the resource sector could also be extended to include the potentially negative and flow-on consequences associated with global climate change [6]; this is outside the scope of this chapter.

\subsection{Health impacts for resource sector employees}

The health impacts for resource sector employees can be roughly divided into two categories: one, the direct risks or hazards related to performing activities on site, or in travelling to a worksite; and two, the indirect impacts that may be related to sleep, nutrition and other lifestyle patterns related to rostering arrangements.

\subsubsection{Direct impacts}

According to [7], the mining industry reported 14.9 compensation claims for serious injuries per 1,000 employees in 2009-10, which is well above the average rate for all industries com- 
bined (at 12.6 claims/1,000 employees). Furthermore, these data may under-represent the actual rate for resource-extraction activities, as many people within the mining industry are employed by construction firms, and thus their claims are logged to the construction sector. Fatalities for the mining industry occurred at a rate of $3.5 / 10,000$ employees, which is also substantially higher than the average for all workers (at 1.9/10,000 employees) [7].

Accidents and injuries associated with the movement of large vehicles and/or the transport of materials remain as the key issue for mining workforces. Data from [8] indicates body stressing represented almost half of the workplace health and safety claims lodged in Australia in 2010-11. Within this, occupations such as machinery operations/drivers, technician/ trade workers and labourers recorded amongst the highest number of insurance claims. Conservative predictions indicate that labour force requirements for mining operations in Australia will increase by 44 per cent between 2010 and 2016, and that growth is likely to be in the at-risk occupations including machinery operators and drivers, followed by technicians and trade workers [9]. As the mining workforce grows to meet production targets and expanded industry activity, it could reasonably be expected that so too, the number of workplace incidents in this category will increase in Australia. On the other hand, the mining sector is also increasing the use of simulation and automation, which may reduce employee exposure to hazards.

There are also a range of other direct health impacts likely to be associated with employment in the resource sector, including exposures to hazardous substances such as silica, dust, caustic products and other substances used in resource extraction, raw materials transport, and minerals processing. A detailed exposition of these is not possible within the limits of this chapter; furthermore, it would appear that statistics on worker exposures are relatively limited, especially in terms of being regionally specific.

\subsubsection{Indirect health impacts}

Occupational fatigue is of particular concern for resource industry workers. The indirect effects of shift-rostering and commuting have received much attention, particularly in Queensland and Western Australia, where there is now a growing a trend for greater proportions of the workforce to be non-resident employees. This requires a commute to the worksite via drive-in, drive-out (DIDO) or fly-in, fly-out (FIFO) arrangements; whereupon (typically) twelve-hour block shifts are undertaken, before returning to mining camps where meals and accommodation are provided. Employees return to their homes located in other centres during the intervening off-shift periods. A recent review [10] synthesized a wide range of available literature and concluded that shift work was associated with higher risk of both coronary and cerebrovascular events, with shift employees having a 23 per cent increased chance of suffering a heart attack and 5 per cent increased chance of experiencing a stroke. These risk factors were maintained after adjustment for socio-economic status, however, the study was conducted across all shift work types (including mining, transport, healthcare and others). An earlier analysis [11] specific to Australian fly-in fly-out mining shift workers, reported that interruptions to sleep and circadian rhythms represented very 
real safety risks, with the performance effects exceeding that of a $0.05 \%$ blood alcohol concentration, particularly near the end of night shifts.

There have been reports of problems with workers binging on alcohol and drugs either at work camps, or within the general community, from Australia as well as internationally (for example [12]). The true extent of vulnerability to drug and alcohol abuse remains difficult to judge given that some reports are anecdotal rather than empirical. States such as Queensland have already identified that high levels of unhealthy behaviours are a key challenge to improving public health [13]; but the contribution of the burgeoning resource-sector to this has never been measured.

There have been some reports to suggest that mining employees are placed at higher risk of contracting infectious disease, as a result of living in close quarters with others in mining camps, as well as the high mobility of the non-resident workers, who may carry diseases into the community from far afield [14].

Mental health concerns appear to be poorly understood in the mining sector [15]. There have been few statistically rigorous empirical studies, but the weight of anecdotal evidence is large and growing. One group has reported a range of mostly negative impacts of FIFO and DIDO arrangements on employee wellbeing, albeit from a small sample size [16]. Here, impacts included implications for primary relationships, inability to participate in organised sport, loneliness, mood swings and disturbed sleep. Indeed, the lack of support that non-resident employees have, sometimes combined with a culture of non-disclosure amongst 'macho' males, is likely to be compounding mental health issues at worksites [15]. By contrast, problems in psychosocial health and wellbeing have been less commonly cited for the resident mining employees. It appears that, compared with non-residents, resident employees enjoy better shift arrangements and report greater job satisfaction and wellbeing levels [17], presumably linked with the ability to receive better support from family and friends, as well as avoiding the strain of travelling.

Finally, the issue of negative reproductive health outcomes for mining workers remains contentious. There have been assertions that mining lifestyles featuring high disposable incomes and extended periods of time away from family can prompt the use of paid sex, triggering rising rates of gonorrhoea, syphilis and chlamydia. However, this has also been argued against, with several authors pointing to a lack of any real evidence, as well as misconceptions about the real nature of sex work and its linkages to sexually transmitted diseases [18-19].

\subsection{Direct impacts on resource regions}

A range of direct health impacts are already known from in communities that host minerals extraction and processing activities. Each phase in the lifecycle of coal production is associated with pollutants that affect human health [6]. In America, residents of coalmining areas face increased risk of cardiopulmonary disease, chronic obstructive pulmonary disease, hypertension and lung and kidney diseases, compared with populations of non-mining regions [20, 21]. The burning of coal for electricity generation is also hazard- 
ous to human health, including workers and community residents. For example, the Australian Academy of Technological Sciences and Engineering [22] estimated that coal burning in Australia was associated with some \$AU2.6 billion in impacts to the national health burden. This included the problems associated with particulate matter as well as NOx and SOx emissions. The modelling used in this report showed the damage cost for both primary and secondary pollutants, and illustrated that the damage costs are roughly proportional to the regional population density [22]. Consequently, as regional populations are swelled by growth in resource-sector jobs, it follows that the regional health burden is also likely to grow.

\subsection{Indirect impacts on resource regions}

\subsubsection{Flow-on impacts to partners and families}

The partners and families of resource sector employees can experience a wide range of adverse health impacts which may be related to having a member of the household working in the resource sector, and/or to living in the resource regions themselves. For example, there are anecdotal reports that child mental health in resource communities is of concern; often, this is linked with the perception that increased rates of marital separation and conflict are associated with shiftwork arrangements in the mining sector. However, [23] reported that the psychosocial wellbeing of children from FIFO families was not adversely impacted by work-related parental absence; rather it more often the remaining parent (typically the mother) who reported difficulties, especially the need to manage family cohesion during long periods of separation. This was echoed by [16] who recorded difficulties for FIFO/DIDO partners, including depression and other emotional challenges that emerge from having to cope whilst the employee was absent during shifts. Noted elsewhere was anecdotal evidence that suggests '...depression, anxiety, post-traumatic stress disorder, social phobias and substance abuse disorders are almost as likely to be found in the stay-at-home partner as they are in the FIFO worker' [15]. Thus, problems of isolation, cultural change and difficult social environments emerge within family units, as well as in the wider community [24]. It is important to note also that FIFO/DIDO arrangements introduce the potential for negative public health outcomes to be experienced beyond resource-region townships, extending instead into the source communities from which the FIFO/DIDO labour is supplied.

Health issues relating to mining 'boom' periods in Canada run in the themes of family health, women's health, mental health, worker's health and health and social services [25]. Specific impacts included concerns about divorce, violence, stress, increased rates of pregnancies (presumably unwanted) and sexually transmitted diseases; sexual harassment and addictions. For women's health, the availability and accessibility of transition housing and maternity care were key issues. The gender imbalance and progressive masculinisation of the workforce is also linked with increasing levels of violence and overconsumption of alcohol [26]. In a recent submission to the Australian Parliamentary Inquiry on DIDO/FIFO work practices, a regional Alcohol, Tobacco and Other Drugs 
Service (ATODS) reported an increase in alcohol-related injuries in Queensland townships [27]. They also recorded a higher incidence of workplace referrals for employees returning positive drug or alcohol tests.

\subsubsection{Flow-on impacts to the wider regional community}

\subsubsection{Increased demand for health infrastructure and services}

Almost all resource-rich areas are located in regional and rural parts of Australia [28]. This is a critical factor when considering the public health implications of resource extraction, because regional areas are already challenged by a broad spectrum of issues related to health services and infrastructure. For example, regional Australia is often challenged by under-resourced health systems, with low service provision, issues of accessibility and quality of care, difficulties in staff attraction/retention, skills shortages, high workloads, a much higher cost of service delivery, and unique case mixes [27, 29]. People living in rural and remote areas also tend to have higher levels of disease risk factors and illness than those in major cities [30]. In particular, rural and remote residents have higher rates of injury mortality, especially road accidents; higher rates of communicable diseases, disability and homicide; and higher rates of smoking and alcohol consumption; with Aboriginal and Torres Strait Islander wellbeing being a particularly challenging issue. Consequently, the cumulative impacts of resource sector development often manifest as additional stress being placed on the aspects of regional health systems that are already under strain.

The increased demand represented by the non-resident workforce is probably the most critical of the impacts that resource sector development has on health services and infrastructure in regional Australia. The key problem here is that the FIFO/DIDO workforce are typically not included in regional statistics, and thus are not accounted for as part of the baseline population loads used to forecast need and allocate government expenditure in resource townships [31]. Unpublished research at Central Queensland University shows regional demographics calculations can substantially underestimated expected growth if the multiplier effects of the mining workforce are not considered. Consequently, health services and infrastructure in resource communities is often inadequate to cater for the rapidly growing populations associated with increased mining activity [32]. This is true for Australia as well as other countries: in Canada, development of the oil sands of northern Alberta has been linked with poor community health outcomes associated with infrastructure deficits, where the municipalities that host mining score worse than the provincial average for health indicators [33].

There are many examples available that illustrate the problems of providing health services and infrastructure in burgeoning resource communities. Recent modelling work done by [34] indicated that health and emergency services provision within Queensland's Bowen Basin is significantly undersupplied because of the combined resident and non-resident demand linked with growth in the resources sector. General practitioners [14] have noted that Central Queensland had the highest doctor-to-patient ratio in the state in July 2009 (1: 1,824), and that this was being exacerbated by the in- 
flux of population related to the resources boom. Records from their private practice at Moranbah (a key centre servicing the Bowen Basin) demonstrate clear increases in the number of non-resident patients seeking care: almost one-quarter of the patients serviced in 2011 were non-resident (that is, had home postcodes outside of the immediate local area), compared with only 18 per cent in 2007. This overburdening means the practice can no longer offer same-day service to the resident population [14]. The authors also highlighted that non-resident patients offer a more challenging case mix, for example, presenting with emergencies due to workplace accidents, fatigue-related road incidents, and/or reckless behaviour (for example drug/alcohol abuse). Furthermore, treating these patients is challenged by the lack of existing relationship with the medical staff, which can result in low cooperation, the danger of drug interaction and/or unidentified allergy risks; and dissatisfaction with perceived 'small town' medical services [14]. The increased burden on health in resource regions is particularly challenging considering that workloads for general practitioners in rural and remote settings are already higher than metropolitan areas [35].

The resource sector is also notable in the ways in which it influences the patterns of demand for health and community services. For example, in Central Queensland, the difficulties in recruiting for the mining labour force from rural and regional Australia has led to an increase in the employment of staff on 457 (skilled migrant) visas. This multicultural influx brings with it new demands in the areas of community wellbeing, such as having access to appropriate places of worship, bilingual counselling, and increased (anecdotal) incidence of mental illness due to isolation from family, and abandonment of the home country (Centacare, personal communication, August 2012). Reference [25] also noted that mining booms can pressure regional health services by changing community demographics.

\subsubsection{Attraction and retention challenges for health-related roles}

A number of challenges are faced in attracting staff to regional health and community services, particularly in resource communities. There are already recognised skills shortages in disability, physicians, nurses and allied health professionals in states such as Queensland, which house a large proportion of Australia's mining activities [36, 37]. The ratio of allied health professionals to the general population of regional centres is approximately half that of metropolitan areas, where staff retention is already a key issue [38]. This arises predominantly because of concerns about the high costs of accommodation, because regional centres that host mining activity often experiencing inflated housing prices [31, 39]. It also reflect a combination of other (often pre-existing) concerns about rural and remote health practice, including high workloads due to pre-existing low staffing levels, mandatory on-call duties, frequent overtime, limited opportunities for professional development, and poor supervision and management support [40]. Each of these can contribute to high stress levels and staff exhaustion ('burnout'), thus prompting staff to leave, and the development of a selfperpetuating cycle. The difficulties in staff attraction/retention due to high costs of living, perceived poor liveability and other issues also has negative flow-on effects in terms of the 
(lack of) continuity of patient care, brought about by the high staff turnover. This may manifest at both administrative (tracking of medical records) and personal levels (personalised follow-up) [41].

\subsubsection{Economic and social costs of service delivery in resource regions}

Rural and regional health services in Australia, especially primary health, already suffer from difficulties in the proper costing of service delivery. In particular, service providers are faced with tricky decisions about local service provision compared with 'outreach' services; this includes not only the economic costs but also other considerations such as employee safety, the likelihood of good patient outcomes, and the challenge of filling positions with appropriate workforce experience and skills. In servicing the burgeoning resource regions of Australia, health sector employees themselves can operate on FIFO/DIDO arrangements. However, there are already concerns about the health and safety of outreach services employees, who may experience similar issues to resource sector shift workers (as mentioned above). Staff may have the need to travel long distances to service resource-based communities, and this places them at safety risks, including extended hours of travel by road in rural areas where mobile coverage is poor; visits to the homes of (unfamiliar) clients in isolated areas; fatigue due to long days and long periods away from home; and challenges finding suitable accommodation, particularly in mining areas where much of the accommodation is booked out months in advance [37, 42].

\subsubsection{Other impacts in resource regions}

The indirect impacts of resource development may also manifest through effects on the natural environment, leading to lost ecosystem services, and the potential for flow-on impacts to human health. For example, in 2011, an outbreak of diseased fish occurred in the Gladstone harbour in Central Queensland, which is currently undergoing extensive dredging and development as part of the growth of the coal seam gas industry. A temporary ban on fishing was enacted, and there was much local concern about whether the fish were fit for human consumption, and the reason(s) for the outbreak. The Queensland government commenced a fish sampling and water quality program, including an investigation into human health concerns and the establishment of a Scientific Advisory Panel [43]; but debate continues as to whether the dredging program is responsible, with other stressors including natural parasites and the entry of floodwaters into the nearshore environment also being cited as possible contributors.

A new term was coined [44] - solastalgia - to represent the "distress that is produced by environmental change impacting upon people while they are directly connected to their home environment". The authors studied the community supporting the Hunter Valley, a region of New South Wales that was experiencing rapid growth in mining and power station developments, and found that resource sector developments can have a substantial impact upon emotional health of regional residents. Here, the residents were reported to experience emotional stress and mental health problems linked with a sense of powerlessness and injustice over the region's development. This problem appears to be particularly acute for 
those with strong connections to the land (such as generational farming families, or Indigenous Australians) [44].

\subsection{Positive impacts and other linkages}

The potential for positive health outcomes from resource development has hardly been studied. It was identified that increased awareness of health and safety was one possible positive outcome of cumulative development [4]. Furthermore, some workers have described the lifestyle and wellbeing benefits that a generous mining salary can provide, and point to strong camaraderie within the workplace as a positive impact of their employment [17]. The higher wages paid to mining employees could also be linked with an increased ability to purchase foods with better nutrition, access higher-quality health care, and spend discretionary income on participation in organised sport and recreational activities. Such linkages have rarely been reported in the literature, but it would seem a reasonable conclusion given that, in some instances, over half the population of resource towns can receive double the national average weekly wage [31]. The apparent lack of any published material in this area may represent a research bias towards reporting of health problems of resource regions, rather than health and wellbeing benefits.

Developed nations such as Australia also have a comparatively tight regulatory environment regarding mining sector operations, and these should reduce the potential for the direct impacts of development on local populations, such as through water or air pollution. This avoids the situation being experienced by some countries, such as Africa, rapid and poorly managed industrialisation is presenting new risks termed modern environmental health hazards (MEHHs). These MEHHs are 'products of rapid development in the absence of health and environment safeguards, as well as the unsustainable consumption of natural resources', and contribute significantly to the environmental disease burden [45].

Another encouraging sign is that there continues to be a strong focus on workplace safety in the resource sector, with particular areas of focus including being fatality-free, recording a minimum of lost time injury, and experiencing low incidence of disease [46]. In demonstrating this commitment, in recent years, the Australian Coal Association Research Program (ACARP) has funded wide-ranging health projects including exploring the dust risks for open cut mining, exhaust emissions from alternative diesel fuels, human health impacts related to the growth of toxic blue-green algae in mining-related water bodies, injury risks with underground coal mining equipment (including ergonomics and high pressure injection injuries), and mine safety regulations [47].

There are already reports of surging growth in businesses in health care and social assistance, for those regions that host resource activity. In Queensland, the health and community services sector is already the state's largest industry employer, representing 11.7 per cent of the state's total labour market [48]. In Central Queensland's Bowen Basin, Australia's premier coal-producing region, data from the Australian Bureau of Statistics shows that the number of health and social services businesses operating in this industry division has grown by almost 20\% over 2008/09 to 2010/11 - the second-fastest growth sector overall, and far greater than the baseline population growth for the same period. 
Finally, the last possible health benefit linked with the resource sector is the potential for improvements to health infrastructure and services, funded from mining royalties. However, it is peculiar to note that proposed trials for the National Disability Insurance (NDI) Scheme were declined by both the Western Australia and Queensland governments - despite those two states hosting the greatest proportions of resource activity in Australia; and the NDI scheme being funded from the newly introduced Minerals and Resources Rent Tax.

\section{Monitoring and measuring cumulative health impacts}

Health Impact Assessments (HIAs) are important tools in policy development and can be used in a wide range of planning and development applications. In their early iterations, health impacts were included as part of broader environmental impact assessment (EIA) processes, and assessments were often limited to quantitative, as opposed to qualitative, risk assessments. This process overlooked broader considerations such as cumulative impacts, intergenerational effects and broader determents of health [49]. Gradually, however, public health assessment has become more inclusive and far-reaching. This occurred first through the change in interpretation of 'environment' to include not only the biophysical elements, but also wider considerations around social, cultural and human health perspectives. Secondly, at the urging of the World Health Organisation, there was a transition for 'health' to imply not only physical health, but also the general state of wellbeing. This allowed for the health components of EIA to include not only disease-related effects, but also all impacts on human wellbeing. In this more 'mature' state, impact assessment approaches have changed with the recognition that physical and social environments are critical determinants of health overall, compared with the earlier focus for risks assessments to quantify the carcinogenic potential of single toxins. However, it can be concluded [50] that environmental health issues were not being sufficiently treated in EIA processes; in particular, while physical health impacts directly caused by environmental change were afforded some consideration, other health determinants in the social sphere were rarely, and often poorly, considered. Additionally, they noted that there is "little evidence to suggest that health concerns, particularly issues associated with social health and quality of life, carry over to the post-decision monitoring stages of the EIA" [50].

\subsection{Health impact assessment in Australia}

Australia has conducted HIA work for over fifteen years [51]. In 1994, a National Health and Medical Research Council (NHMRC) report emphasised that health impacts deserved special attention within EIA processes; this was followed by the publication of enHeath HIA guidelines [52] and later, the development of an equity-focused HIA framework [53, 54]. In the latter, the 'equity' approach acknowledges that vulnerable groups have special health needs, and may experience particular health impacts; it also recognises that health and wellbeing are linked with where people live, work and play [55]. Australia is now considered a leading nation in considering equity within HIAs [56]. 
Specific tools to identify and manage health impacts in their own right have been developed only relatively recently (since the 1990s onwards); and decision-making tools for HIA emerged in the early 2000s [49]. Most recently, in 2007, the Australian Government published a practical guide of HIA, which encourage a scope beyond environmental health, and into the broader perspectives of health determinants [56, 57]. Unfortunately, the good progress that Australia appears to have been made with HIAs overall does not appear to have been translated into managing health impacts specifically related to resource development activities.

\subsection{Impact assessment for resource development activities}

The disruptive nature of extractive resource activity means that particular care must be taken to understand the likely impacts of project development, and to manage them throughout the various phases of activity (construction, operations, and decommissioning). In Australia, EIA tools have been used as part of mining development applications since the pre-1980s. Whilst health impacts can be assessed and monitored within the EIA process, this is typically limited to physical risks and hazards, and rarely do the terms of reference for EIAs actually prescribe a section on health impacts. For example, current EIA statements typically include an assessment of impacts across areas such as land, water or air contamination; noise and vibration; traffic and transport and largely ignore the health and social issues [58,59]. Project proponents are also required to prepare environmental management plans (EMPs), which partly cover health impact issues, albeit with an environment focus.

Social Impact Assessments (SIAs) have also been introduced into Australian planning and development processes. Here, the SIA process sets out to analyse the potential social consequences of projects on demographics, behaviours, social services and aspects of community wellbeing and lifestyle. Therefore, similarly to EIAs, the use of SIA tools could include some consideration of broader health impacts, particularly the indirect effects to community infrastructure and services (as described above). In Queensland, a key state for resource activity, this now includes the preparation of a companion Social Impact Management Plan (SIMP). However, undertaking HIA appears to be still at the experimental stage, being undertaken on an ad hoc basis if at all [60]. Confusingly, there is no clear guidance as to whether health impacts should be monitored within EMPs or SIMPs, or instead, whether a purpose-built Health Impact Management Plan (HIMP) is required. The issue of assessing cumulative impacts also remains unresolved, with no standard methodology for the assessment of cumulative impacts as part of either EIS or SIA reports; and nor are there specific legislative requirements as to how cumulative impacts should be addressed. In part, this may reflect the complex nature of cumulative impacts, which vary in severity and duration, depending on the timing, duration and number of concomitant construction and operational activities. Nevertheless, the weight of evidence relating to cumulative impacts clearly demonstrates the need for innovative methodological approaches to be developed, such that the range of impacts, including health impacts, can be properly accounted for during planning, approvals and operational phases. 


\section{Developing better systems to monitor, predict and manage cumulative health impacts from resource activity}

The rapid pace of resource development in many Australian regions means that suitable frameworks and monitoring tools for public health impacts need to be developed urgently. Already, current data suggest that regional health infrastructure and services are overburdened and unable to cope with the rapid population growth that accompanies growth in the resource sector; let alone able to cater for new case mixes related to cumulative impacts. Despite this, adoption of cumulative health impacts has yet to be fully supported, particularly in legislation, across the varying levels of government in Australia [51] (Table 1).

\begin{tabular}{|c|c|}
\hline $\begin{array}{l}\text { Legislation and/or } \\
\text { Terms of Reference }\end{array}$ & as \\
\hline $\begin{array}{l}\text { Commonwealth } \\
\text { Environment Protection } \\
\text { and Biodiversity } \\
\text { Conservation Act } 1999 \\
\text { (March 2010) }\end{array}$ & $\begin{array}{l}\text { No specific mention of cumulative impacts; though the Act requires } \\
\text { consideration of 'reasonably foreseeable indirect impacts' by third parties. } \\
\text { Impact is defined to include direct, indirect and reasonably foreseeable } \\
\text { consequences of actions. Federal court rulings have interpreted the act to } \\
\text { include cumulative impacts. The Hawke review of the EPBC act has signalled } \\
\text { that cumulative impacts will be a focus of reform. }\end{array}$ \\
\hline $\begin{array}{l}\text { Queensland Environmental } \\
\text { Protection Act } 1994\end{array}$ & $\begin{array}{l}\text { The Act makes no distinction between cumulative or other impacts, but } \\
\text { expects an EIS to assess all such impacts. The draft ToR must be 'in the } \\
\text { approved form.' In practice this means that project ToR must be based on the } \\
\text { generic ToR developed by the Department of Environment and Natural } \\
\text { Resource Management. }\end{array}$ \\
\hline $\begin{array}{l}\text { Qld Department of } \\
\text { Environment and Resource } \\
\text { Management, Generic Terms of } \\
\text { Reference for impact assessment } \\
\text { statements } \\
\text { (2010) }\end{array}$ & $\begin{array}{l}\text { The generic ToR does not require a separate section for cumulative impacts, } \\
\text { but rather requires them to be assessed in issue-related sections, such as those } \\
\text { for ecology, social impacts, or noise. For example, indicative extracts from the } \\
\text { generic ToR include: } \\
\text { "Describe any cumulative impacts on environmental values caused by the } \\
\text { project, either in isolation or by combination with other known existing or } \\
\text { planned development or sources of contamination." } \\
\text { "The cumulative impacts of the project must be considered over time or in } \\
\text { combination with other (all) impacts in the dimensions of scale, intensity, } \\
\text { duration or frequency of the impacts". } \\
\text { "Where impacts from the project will not be felt in isolation to other sources } \\
\text { of impact, it is recommended that the proponent develop consultative } \\
\text { arrangements with other industries in the proposal's area to undertake } \\
\text { cooperative monitoring and/or management of environmental parameters. }\end{array}$ \\
\hline $\begin{array}{l}\text { State Development and Public Work } \\
\text { Organisation Act } 1971\end{array}$ & $\begin{array}{l}\text { This Act addresses impacts associated with State Significant projects (as } \\
\text { defined under the Act. However, there is no specific mention of cumulative } \\
\text { aspects (except in environmental assessment of fishing activities). }\end{array}$ \\
\hline
\end{tabular}

Table 1. Examples of legislative considerations related to the assessment and monitoring of cumulative impacts in Australia and Queensland (ToR = Terms of Reference). 
Monitoring programs for cumulative health effects are already in effect in regions of Canada (for example in Saskatchewan), where the focus is on detecting air, water and food web contamination. However, in Australia, monitoring programs could be designed to provide data that underpins decision-making across a broad range of health objectives. For example, these might include developing healthy lifestyles and social cohesion, and ensuring good housing quality, accessibility to health services, safety, equity, and appropriate air and water quality [61]. It could also cater for wider community development issues linked with good health outcomes, such as impacts on regional health workforce planning. It's been recommended [62] that HIAs associated with extractive industries should include a wide description of the environmental health areas impacted upon by the development, the extent of impact, as a spatial delineation of the potentially affected communities. For example, this would include traditional indicators such as communicable diseases; vector-borne illnesses; soil, water and waste-related diseases; sexual and reproductive health; food and nutrition related issues; as well as accidents and injury, hazardous exposures. Most importantly, the authors also noted the importance of considering social determinants of health, cultural health practices and health system issues as being important, and developed an innovative HIA methodology for how these could be considered in a developing-nations context [62].

Once key classes of impacts have been identified, it also would be particularly useful to determine how many people are likely to be affected. Considering the rapid and ongoing growth of the resources sector, and the regional population growth that often accompanies economic booms, it is likely that an increasing number of regional Australians will be affected by the health impacts of resource development. For example, unpublished research by CQUniversity suggests that future projections might be prepared based on expected industry growth (nature and volume of project expansion), as well as the multiplier effect that this creates for regional population growth.

Understanding and predicting cumulative effects is a challenging science, requiring both spatial and temporal considerations [5]. For cumulative public health, this also means understanding the dynamics of exposed (or potentially exposed) population groups and subgroups. It is particularly important to recognise that some population cohorts are likely to be at greater risk and disadvantage with respect to cumulative health impacts of resource development. For example, 'social apartheid' can develop in resource regions, where people with a disability, Indigenous and culturally and linguistically diverse (CALD) communities experience greater difficulty in accessing services (such as health services), compared with the general population [63]. Also, migrants have already been identified as being of greater risk of mental health disorders in resource regions [15]. This is of note given that some $18.5 \%$ of Australians have a disability [64], and 20.4\% identify as CALD (speaking more than one language at home [65]. Other key groups that may be impacted include women, sole parents and the aged; and people who fit into more than one of the above categories would be considered to be at greater and more complex disadvantage. Unfortunately, there is a paucity of empirical data regarding the impacts on such groups, with work on the effects of mining on First Nations people in Canada being a notable exception [66]. Here, the concerns included issues around pollution of traditional food and water sources (by arsenic and mercury for 
example), and departure from the traditional diet to favour processed foods because of fears about hunting and/or gathering nearby to mining shafts, processing equipment and tailings ponds [66]. Others [12], have explored the effects of resource-extraction specifically on young people's health in the oil and gas communities of British Colombia, reporting that low education levels, addictions (alcohol, drugs) and high costs of housing were key impact areas. In Australia, new evidence is also emerging from the Parliamentary Inquiry mentioned above: for example, the following comments were made by [67]:

"...medical and dental services across Whitsunday, Isaac and Mackay have become increasingly difficult to access, particularly for low to middle income earners. The deficits include only one dentist in Moranbah, which is currently at risk of closure due to tenancy/rental issues; no pre-natal services in Bowen; (and) no full bulk billing GP surgeries in Mackay and Whitsunday or Moranbah. This significantly disadvantages youth, people with a disability, older people and low income earners."

In Australia, the options for introducing health impact assessments specifically for resource sector development in regional areas appear to be either (a) include better articulation of health impacts in the existing terms of reference for EIA or SIA processes; or (b) introduce a third impact assessment approach that specifically addresses health concerns. In both cases, overlap amongst the approaches may be a problem; and it must also be noted that both would represent an increased reporting and administrative burden on proponents and the government planning and development departments. Incorporating cumulative health impacts into existing management plans may help to streamline the process, but it must also be noted that this could result in the work being done by non-health specialists.

In considering new approaches for cumulative health impact assessments, the potential contribution of strategic-level assessments is also important for good health outcomes, given that strategic assessments are often promoted as a tool that more effectively accounts for cumulative impacts. For example, the advantages of undertaking health assessments at the wider (policy and planning) level, include:

- early consideration of health matters in planning processes

- greater certainty to the local communities and developers over future development

- reduced administrative burden for proponents and government

- capacity to achieve better health outcomes and

- the ability address cumulative impacts at the regional level.

Evaluation of impacts and communication with stakeholders about the impacts outcomes is an important aspect of managing cumulative health impacts. The number of parameters to be monitored will depend upon the potential likelihood and magnitude of the health impacts. At the same time, coordination with stakeholders particularly between the proponents, government agencies (for example health and environment agencies) and the affected 
community is important [68] to effectively manage the cumulative impacts. While monitoring is the responsibility of proponents, routine surveillance from environment and health sectors is also warranted. Furthermore, if health, allied health and social community/services sectors are to be properly integrated into this processes, it would be useful to identify (or in some cases, establish) peak representative groups for the key subsectors, so that consultation during development approvals can be done effectively, rather than proponents trying to engage with individual service providers.

With respect to engaging the mining sector itself, there is already strong motivation for their interest and participation in health impact assessments, even if these remain outside of current regulatory requirements. Improving employee health and wellbeing is of direct benefit to mining proponents, who may experience improved morale, reduced absenteeism, reduced staff turnover and improved productivity [15]. Engagement in the health area is also likely to pay dividends in terms of the 'social licence to operate'. Recommendations from north-west Queensland [69] encourage the use of the Framework for Health Promotion to help engage with resource sector employees and begin identifying and addressing workplace health and safety issues. Direct partnerships between mining companies and health service providers has also been suggested as one way to address the public health concerns linked with 'mining booms', particularly in the areas of health promotion and health education [12]. For example, some authors [25] have noted 'mine(s) and health authorities could engage in joint training (for) healthy living, workplace safety, nutrition ... a focus on a preventative approach'. A close examination of shift schedules and the impacts of these on worker's health, as well as flow-on impacts to partners and families, has also been called for [25].

Finally, the use of zoning may be useful in facilitating the monitoring and measurement of health impacts of a particular regional area, in a cost-effective fashion. For example, a Cumulative Management Area has been established within the Surat Basin for the purposes of managing groundwater impacts arising from the multiple coal seam gas leases now in operation [70].

\section{Areas for further study}

There is a severe lack of peer-reviewed material regarding environmental health from Australian resource regions [6]. There are a paucity of studies on the health impacts of existing industry, let alone the possible health benefits of new technologies used in the mining sector, or even or alternative industry sectors altogether. Furthermore, the research that has been done to date often appears constrained by relatively low sample sizes or a focus on physical safety and physical health. The lack of empirical evidence presented to the Australian Parliamentary Inquiry is of particular note, with most submissions reliant on anecdotal reports of impacts. This lack of data has implications for record-keeping, data collection and/or data availability for EIA and/or SIA practitioners; as in many cases, understanding of impacts could be significantly improved through the collection of relatively simple data. An 
extraordinarily good example of this is recording the postcode of residence for patients being treated in resource-regions, as done by Moranbah Medical [14], as this is a good indicator of the pressures that resource-sector employees add to regional health services. Comparing incidence rates of key issues, such as mental and reproductive health problems, in the pre-boom and post-boom phases of construction and operation may also help to identify particular health issues that are heavily linked with resource sector activity.

Specific research challenges in the area of cumulative health effects from resource development activity therefore include:

- a need for systematic and comprehensive data collection on environmental health concerns, both for employees as well as residents;

- a need to understand the role of cumulative impacts on not only physical health, but also mental health, community wellbeing;

- the development of appropriate techniques for assessing cumulative human health impacts, which has been severely lacking to date $[58,71]$.

The latter includes the need to model and forecast the likely influence of resource sector development on regional development dynamics, especially with respect to population growth, and the expected trends for disadvantaged groups who may require specialised services and infrastructure.

Each of these are complex issues: whilst it is already well known that the mining boom has been generating social and economic impacts, the patterns of impacts appear to vary across communities depending on the size of the impact, community structure and history, and the extent to which a non-resident workforce is involved [72]. Furthermore, as noted by [29]: 'rural and remote health is complex ... (a) web of individual actions, community control, local culture, government regulation from several levels, risk management in various ways and a combination of autonomy and surveillance at all levels'.

Two further areas of study should also revolve around what constitutes good practice for the assessment of cumulative health impacts, as well as how the division of responsibility for health should be tackled between project proponents, government and community. For the former, A Good Practice Guidance on Health Impact Assessment is already available [73], but it not clear that this adequately considers cumulative impacts, especially in the context of resource sector development.

Finally, in addition to the establishment of a framework (legislation, administrative guidelines, and infrastructure) for applying HIA, the development of appropriate training, workforce development programs and broader capacity within organisations to undertake HIA is of growing concern. There is a case to ensure that cumulative impacts are identified in the training curriculum so that practitioners are aware of this emerging issue. The general visibility of environmental health requires consideration in Australia; these skill sets are needed across a range of career domains including occupational health and safety, psychology, environmental science, nursing and regional planning, so there is the potential for wider teaching of environmental health across a range of undergraduate and postgraduate programs. 
The incorporation of environmental health experts into committees and panels responsible for preparing, and/or approving the impact assessments drafted for resource sector activities, has been a missing element in the past [74]. Introducing this in Australia (and elsewhere) would help to ensure that the plethora of direct and indirect health impacts linked with resource development are better identified, and generate a focus on mitigating negative outcomes as well as maximising any opportunities for public health benefits.

\section{Conclusions}

The cumulative health impacts of large-scale resource development are emerging as a key challenge for regional Australia. Mining employees, their partners and families, and the residents of resource regions each face a multitude of public health challenges linked with the resource sector. However, there is a lack of research data regarding employee and public health impacts in resource communities. This is a critical information gap in preparing social and environmental impact assessments, and is likely to be a key constraint in developing the accompanying management and mitigation plans. The severity of this problem is particularly highlighted when the lack of empirical data is contrasted with the large quantity of available anecdotal data, as shown by the recent submission to an Australian Parliamentary Inquiry.

The health impacts experienced by resource regions are further exacerbated by the fact that resource development activity in Australia is almost entirely located in rural and remote settings where there are already health service and infrastructure constraints, as well as fewer opportunities to access preventative health care and public health education. The expected ongoing and rapid growth in the mining sector, and the potential for multiple developments to occur in close physical and temporal proximity, introduces a further level of complexity to this challenge.

Introducing stronger and clearer requirements for the identification of cumulative health impacts within planning and development processes would be useful way to begin tacking the range of effects experienced by resource-regions. This should include a consideration of whether health impacts can be properly accommodated in existing processes (EIAs or SIAs) or whether a de novo health assessment process for resource sector activity is required. Regardless of which option is selected, there a number of mechanical issues that must be worked through, including how best to simultaneously streamline the process, ensure rigour, engage effectively with stakeholders and ensure that assessments are effective for capturing cumulative, regional-level impacts. In the short term, one practical recommendation is to ensure that EIA/SIA teams included environmental health experts.

Highlighting the cumulative health impacts of resource sector activity is an important step in working to improve the health of the population in regional Australia. It represents a good channel to increase the policy focus on regional health impacts; which may include better consideration within the 'health' portfolio, but also a number of others including those for workforce development, community services and regional development more generally. It represents a good opportunity to develop a sound business case for investment of the wealth created by the resources industry, in order to avoid adverse public health outcomes that accompany resource development. 


\section{Author details}

Susan Kinnear ${ }^{1^{*}}$, Zobaidul Kabir ${ }^{1}$, Julie Mann ${ }^{1}$ and Lisa Bricknell ${ }^{2}$

*Address all correspondence to: s.kinnear@cqu.edu.au

1 CQUniversity Australia, Centre for Environmental Management, North Rockhampton, Australia

2 CQUniversity Australia, School of Health and Human Services, North Rockhampton, Australia

\section{References}

[1] DEEWR. Resourcing the future National Resources Sector Employment Taskforce Discussion Paper, March 2010. Department of Education, Employment and Workplace Relations: Commonwealth of Australia; 2010.

[2] BREE. Resources and Energy Quarterly, March Quarter 2012. Bureau of Resources and Energy Economics: Australian Government: Canberra; 2012.

[3] Shan D. Maximising growth in a mining boom. Minerals Council of Australia; 2012.

[4] Franks DM, Brereton D, Moran CJ, Sarker T, Cohen T. Cumulative impacts - a good practice guide for the Australian Coal Mining Industry. Centre for Social Responsibility in Mining \& Centre for Water in the Minerals Industry: Sustainable Minerals Institute: The University of Queensland: Australian Coal Association Research Program: Brisbane; 2010.

[5] INAC. A Citizen's Guide to Cumulative Effects. Department of Renewable Resources and Environment: Indian and Northern Affairs Canada; 2007.

[6] Castleden W, Shearman D, Crisp G, Finch P. The mining and burning of coal: effects on health and the environment. Medical Journal of Australia 2011;195(6) 333-335.

[7] Safe Work Australia. Key Work Health and Safety Statistics Booklet 2012. Safe Work Australia; 2012.

[8] SRCC. Compendium of OHS and Worker's Compensation Studies December 2011. Safety, Rehabilitation and Compensation Commission: Commonwealth of Australia: Canberra: ACT; 2011.

[9] Skills Australia. Employment Growth Projections in Mining Operations (less oil and gas), 2010-2016. Australian Workforce Productivity Agency; 2011. http:// www.awpa.gov.au/sector-specific-skill-needs/resource-sector-skills/employment-estimates/employment-estimates.html (accessed August 2012) 
[10] Vyas MV, Garg AX, Iansavhicus AV, Costella J, Donner Al, Laugsand LE, Janskzy I, Mrkobrada M, Parraga G, Hackam DG. Shift work and vascular events: systematic review and meta-analysis. British Medical Journal 2012; 345.

[11] Muller R, Carter A, Williamson A. Epidemiological diagnosis of occupational fatigue in a fly-in fly-out operation of the mineral industry. Annals of Occupational Hygiene 2008;52(1) 1-10.

[12] Goldenberg SM, Shoveller JA, Koehoorn M, Ostry AS. And they call this progress? Consequences for young people of living and working in resource-extraction communities. Critical Public Health 2010;20(2) 157-168.

[13] Queensland Health. The Health of Queenslanders 2010, Third Report of the Chief Health Officer. Queensland Government: Brisbane; 2010.

[14] Scholtz J, Nieuwoudt R. Medical Services in Moranbah and the impact of non-resident workers, submission to the House of Representatives Standard Committee on Regional Australia, Inquiry into the use of 'fly-in, fly-out' (FIFO) workforce practices in regional Australia by Moranbah Medical. September 2011. http:// aphref.aph.gov.au/house/committee/ra/fifodido/subs.htm (accessed August 2012)

[15] Bowers J. Mental health is critical to safety and productivity in Australian mining operations. In: Brereton D, Pesce D, Abogabir X. (eds.) Proceedings of the First International Seminar on Social Responsibility in Mining, 19-21 October 2011, Santiago, Chile; 2011.

[16] Torkington AM, Larkins S, Gupta TS. The psychosocial impacts of fly-in fly-out and drive-in drive-out mining on mining employees: A qualitative study. Australian Journal of Rural Health, 2011;19 135-141.

[17] Mclean KN. Mental health and well-being in resident mine workers: Out of the fly-in fly-out box. Australian Journal of Rural Health 2012;20 126-130.

[18] Scott J, Minichiello V. Mining, sex work and STIs: why force a connection? The Conversation; 8 August 2012. http://theconversation.edu.au (accessed August 2012)

[19] Scarlet Alliance. Submission to the House of Representatives Standard Committee on Regional Australia, Inquiry into the use of 'fly-in, fly-out' (FIFO) workforce practices in regional Australia. Scarlet Alliance; October 2011. http://aphref.aph.gov.au/house/ committee/ra/fifodido/subs.htm (accessed August 2012)

[20] Hendryx M. Mortality from heart, respiratory, and kidney disease in coal mining areas of Appalachia. International Archives of Occupational and Environmental Health 2009;82 243-249.

[21] Hendryx M, Ahern MM. Relations between Health Indicators and Residential Proximity to Coal Mining in West Virginia. American Journal of Public Health 2008;98 669-671. 
[22] ATSE. The Hidden Costs of Electricity: Externalities of Power Generation in Australia. The Australian Academy of Technological Sciences and Engineering; 2009.

[23] Kaczmarek EA, Sibbel AM. The psychosocial well-being of children from Australian military and fly-in/fly-out (FIFO) mining families. Community, Work and Family 2008;11(3) 297-312.

[24] Lovell J, Critchley J. Women living in a remote Australian mining community: exploring their psychological well-being. Australian Journal of Rural Health 2010;18(3) 125-30.

[25] Janis AS, Marcello MV, Jean S, Malcolm S, Mieke K. Perspectives on community health issues and the mining boom-bust cycle. Resources Policy 2011;36 178-186.

[26] RSDC. Social issues relating to permanent and non-permanent residents in the Moranbah mining community, report on behalf of Isaac Regional Council. Regional Social Development Centre; 2011.

[27] QNU. Queensland Nurses' Union Submission to the House of Representatives Standard Committee on Regional Australia, Inquiry into the use of 'fly-in, fly-out' (FIFO) workforce practices in regional Australia. Queensland Nurses' Union; October 2011. http://aphref.aph.gov.au/house/committee/ra/fifodido/subs.htm (accessed August 2012)

[28] Carrington K, Pereira M. Assessing the social impacts of the resources boom on rural communities. Rural Society 2011;21(1) 2-20.

[29] Bourke L, Coffin J, Fuller J, Taylor J, Editorial for the Rural Health Special Issue of Rural Society. Rural Society 2010;20(1) 1-9.

[30] AIHW. Health status of population groups, Australia's health 2010, Australian Institute of Health and Welfare, June 2010. Canberra: Australian Government; 2010.

[31] ABS. Catalogue 4102.0 - Australian Social Trends, 2008 - Towns of the Minerals Boom. Australian Bureau of Statistics; 2008. www.abs.gov.au (accessed August 2012)

[32] Schandl H, Darbas T. Surat Basin Scoping Study: Enhancing regional and community capacity for mining and energy driven regional economic development, Report to the Southern Inland Queensland Area Consultative Committee and Australian Government Department of Infrastructure, Transport, Regional Development and Local Government. CSIRO Sustainable Ecosystems: Canberra; 2008.

[33] Gosselin P, Hrudey SE, Naeth MA, Plourde A, Therrien R, Van Der Kraak G, Xu Z. Environmental and health impacts of Canada's oil sands industry. The Royal Society of Canada Expert Panel: December 2010.

[34] KPMG. Redefining regional planning: managing change, measuring growth (Abridged report for Isaac Regional Council). KPMG; 2011. 
[35] McGrail MR, Humphreys JS, Joyce CM, Scott A, Kalb G. How do rural GPs' workloads and work activities differ with community size compared with metropolitan practice? Australian Journal of Primary Health 2011;18(3) 228-233.

[36] HACSWC. Health and community services industry skills report: August 2011. Health and Community Services Workforce Council: Brisbane; 2011.

[37] NRHA. Submission to the House of Representatives Standard Committee on Regional Australia, Inquiry into the use of 'fly-in, fly-out' (FIFO) workforce practices in regional Australia. National Rural Health Alliance; October 2011. http:// aphref.aph.gov.au/house/committee/ra/fifodido/subs.htm (accessed August 2012)

[38] Chisholm M, Russell D, Humphreys J. Measuring rural allied health workforce turnover and retention: What are the patterns, determinants and costs? Australian Journal of Rural Health 2011;19 81-88.

[39] Rolfe J, Miles B, Lockie S, Ivanova G. Lessons from the Social and Economic Impacts of the mining boom in the Bowen Basin 2004-2006. Australasian Journal of Regional Studies 2007;13(2) 134-153.

[40] Opie T, Dollard M, Lenthall S, Wakerman J, Dunn S, Knight S, MacLeod M. Levels of occupational stress in the remote area nursing workforce. Australian Journal of Rural Health 2010;18 235-241.

[41] NSW Rural Doctor's Network. Submission to the House of Representatives Standard Committee on Regional Australia, Inquiry into the use of 'fly-in, fly-out' (FIFO) workforce practices in regional Australia. New South Wales Rural Doctor's Network; September 2011. http://aphref.aph.gov.au/house/committee/ra/fifodido/subs.htm (accessed August 2012)

[42] Autism Queensland. Submission to the House of Representatives Standard Committee on Regional Australia, Inquiry into the use of 'fly-in, fly-out' (FIFO) workforce practices in regional Australia, April 2012. 2012. http://aphref.aph.gov.au/house/ committee/ra/fifodido/subs.htm (accessed August 2012)

[43] DAFF. Expanded fish health survey interim report June/July 2012. Department of Agriculture, Fisheries and Forestry: Queensland Government: Brisbane; 2012.

[44] Albrecht G, Sartore G, Connor L, Higginbotham N, Freeman S, Kelly B, Stain H, Tonna A, Pollard G. Solastalgia: the distress caused by environmental change. Australasian Psychiatry 2007;15 S95-8.

[45] Nweke OC, Sanders WH. Modern Environmental Health Hazards: A Public Health Issue of Increasing Significance in Africa. Environmental Health Perspectives 2009;117(6) 863-870.

[46] Mineral Council of Australia. MCA Annual Report 2011. Mineral Council of Australia: Australia; 2011. 
[47] ACARP. Australian Coal Association Research Program Reports. Australian Coal Association Research Program; 2012. www.acarp.com.au (accessed August 2012)

[48] Queensland Government. The health and community services industry - building a stronger economy and a fairer Queensland, The Queensland Compact towards a fairer Queensland. Heath and Community Services Workforce Council; February 2012.

[49] Harris P, Spickett J. Health impact assessment in Australia: A review and directions for progress. Environmental Impact Assessment Review 2011;31 425-432.

[50] Noble B, Bronson J. Integrating Human Health into Environmental Impact Assessment: Case Studies of Canada's Northern Mining Resource Sector. Arctic 2005;58(4) 395-405.

[51] Harris P. Health Impact Assessment: the State of the Art. Impact Assessment and Project Appraisal 2012;30(1) 43-52.

[52] National Public Health Partnership. Health Impact Assessment Guidelines. Commonwealth of Australia; 2001.

[53] Mahoney M, Simpson S, Harris E, Aldrich R, Stewart-Williams J. Equity Focused Health Impact Assessment Framework. Australasian Collaboration for Health Equity Impact Assessment: Newcastle; 2004.

[54] Harris-Roxas B, Simpson S, Harris E. Equity Focused Health Impact Assessment: A literature review. CHETRE: Sydney; 2004.

[55] Vohra S. International perspective on health impact assessment in urban settings. NSW Public Health Bulletin year;18(9-10) 152-154.

[56] Harris B, Viliani F, Bond A, Cave B, Divall M, Furu P, Harris P. Overview of Health Impact Assessment Practice in Australia, World Congress on Risk 2012: Risk and Development in a Changing World, 18-20 July, Sydney, Australia, 2012.

[57] Mahoney M. Health Impact Assessment in Australia. NSW Public Health Bulletin 2007;16(7-8) 113-114.

[58] Steinemann A. Rethinking human health impact assessment, Environmental Impact Assessment Review, 2000;20(6) 627-45.

[59] Kabir SMZ, Momtaz S. The quality of Environmental Impact Statements and the environmental impact assessment practice in Bangladesh. Impact Assessment and Project Appraisal 2012;30(2) 94-99.

[60] Morgan RK. Health and impact assessment: Are we seeing closer integration? Environmental Impact Assessment Review 2011;31(4) 404-411.

[61] Barton H, Tsourou C. Healthy urban planning: a WHO guide to planning for people. Spon Press on behalf of the World Health Organisation: Regional Office for Europe: London; 2000. 
[62] Winkler MS, Divall MJ, Krieger GR, Balge MZ, Singer BH, Utzinger J. Assessing health impacts in complex eco-epidemiological settings in the humid tropics: Advancing tools and methods. Environmental Impact Assessment Review 2010;30 52-61.

[63] Goggin G, Newell C., editors. Disability in Australia: Exposing a Social Apartheid. UNSW Press: Sydney; 2004.

[64] ABS. Catalogue 4430.0 - Disability, Ageing and Carers, Australia: Summary of Findings, 2009. Australian Bureau of Statistics; 2009. www.abs.gov.au (accessed August 2012.

[65] ABS. Census QuickStats Australia profile. Australian Bureau of Statistics; 2001 and 2012. www.censusdata.abs.gov.au (accessed August 2012).

[66] IHRC. Bearing the burden: the effects of mining on First Nations in British Columbia. International Human Rights Clinic: Harvard Law School: 2010.

[67] Regional Social Development Centre, Submission to the House of Representatives Standard Committee on Regional Australia, Inquiry into the use of 'fly-in, fly-out' (FIFO) workforce practices in regional Australia. New South Wales Rural Doctor's Network; September 2011. http://aphref.aph.gov.au/house/committee/ra/fifodido/ subs.htm (accessed August 2012)

[68] Kabir SMZ. A critical review of environmental impact assessment system in Bangladesh using a holistic approach. University of Newcastle; 2012.

[69] Devine SG, Muller R, Carter A. Using the Framework for Health Promotion Action to address staff perceptions of occupational health and safety at a fly-in/fly-out mine in north-west Queensland. Health Promotion Journal of Australia 2008;19(3) 196-202.

[70] Department of Environment and Heritage Protection, Cumulative Management Area, 2012, http://www.ehp.qld.gov.au/management/coal-seam-gas/cumulativemanagement.html (accessed September 2012).

[71] Mcintyre L, Petticrew M. Methods of Health Impact Assessment: a literature review. Occasional Paper: MRC Social \& Public Health Sciences Unit: University of Glasgow: UK; 1999.

[72] Petkova V, Lockie S, Rolfe J, Ivanova G. Mining developments and social impacts on communities: Bowen Basin case studies. Rural Society 2009;19(3) 211-228.

[73] ICMM. Good Practice Guidance on Health Impact Assessment. International Council on Mining and Metals; 2010. http://www.icmm.com/library/hia (accessed August 2012)

[74] Goldstein BD, Kriesky J, Pavliakova B. Missing from the Table: Role of the Environmental Public Health Community in Governmental Advisory Commissions Related to Marcellus Shale Drilling. Environmental Health Perspectives 2012; 120(4) 483-486. 